DIGITALCOMMONS - @WAYNESTATE -
Clinical Research in Practice: The Journal of Team Hippocrates

2017

\title{
Compared to maximal current management standards, oscillating positive expiratory pressure devices have not been shown to improve clinically relevant outcomes in COPD patients with acute exacerbation
}

Daniel P. Noack

Wayne State University, dnoack@med.wayne.edu

Gaybriel Newton

Annapolis Family Medicine Residency - Beaumont Health, gaybriel.newton@beaumont.org

Follow this and additional works at: https://digitalcommons.wayne.edu/crp

Part of the Medical Education Commons, and the Translational Medical Research Commons

\section{Recommended Citation}

NOACK DP, NEWTON G. Compared to maximal current management standards, oscillating positive expiratory pressure devices have not been shown to improve clinically relevant outcomes in COPD patients with acute exacerbation. Clin. Res. Prac.

2017;3(2):eP1516. doi: 10.22237/crp/1498867320 


\title{
Compared to maximal current
}

\section{management standards, oscillating}

positive expiratory pressure devices have

not been shown to improve clinically

relevant outcomes in COPD patients with

acute exacerbation

DANIEL P. NOACK, Wayne State University School of Medicine, dnoack@med.wayne.edu

GAYBRIEL NEWTON, MD, Annapolis Family Medicine Residency - Beaumont Health, gaybriel.newton@beaumont.org

\begin{abstract}
A critical appraisal and clinical application of Ambrosino N, Callegari G, Galloni C, Brega S, Pinna G. Clinical evaluation of oscillating positive expiratory pressure for enhancing expectoration in diseases other than cystic fibrosis. Monaldi Arch Chest Dis. 1995;50(4):269-275.
\end{abstract}

Keywords: $\quad$ COPD, PEP, oscillating positive expiratory pressure, acute exacerbation, bronchiectasis, indication creep

\section{Clinical Context \\ This is a 68-year-old male with COPD and chronic hypoxic respiratory failure on tamoxifen. He presented to the emergency room with shortness of breath and wheezing on examination. He was subsequently hospitalized for acute COPD exacerbation, for the third time in a month. The patient was started on standard medications for acute COPD exacerbation, including systemic corticosteroids, antibiotics, and scheduled short acting beta agonists. Despite appropriate medical therapy, the patient continued to have shortness of breath as well as a congested cough without sputum production. The patient was unable to tolerate chest physiotherapy, so his respiratory therapist gave him a breathing device in order to "help him clear his mucus and get better faster." The respiratory therapist described the device as a "flutter valve," which would use mechanical pressure to dislodge the sputum from his airways.}

\section{Clinical Question}

Does the use of oscillating positive expiratory pressure devices improve clinically relevant outcomes when compared to current management standards in patients with acute exacerbation of COPD?

DANIEL P. NOUCK is a fourth year medical student at Wayne State University School of Medicine. GAYBRIEL NEWTON, MD is a third year resident at Annapolis Family Medicine Residency, Beaumont Wayne Hospital. 
NOACK DP, NEWTON G. Compared to maximal current management standards, oscillating positive expiratory pressure devices have not been shown to improve clinically relevant outcomes in COPD patients with acute exacerbation. Clin. Res. Prac. 2017;3(2):eP1516. doi: 10.22237/crp/1498867320
Clinical Research in Practice The Journal of Team Hippocrates

VOL 3 ISS 2 / eP1516 / AUGUST 23, 2017 doi: $10.22237 / \mathrm{crp} / 1498867320$

\section{Research Article}

Ambrosino N, Callegari G, Galloni C, Brega S, Pinna G. Clinical evaluation of oscillating positive expiratory pressure for enhancing expectoration in diseases other than cystic fibrosis. Monaldi Arch Chest Dis. 1995;50(4):269-275.

\section{Related Literature}

We looked at the manufacturer's device information for the brand name and characterization of the device. The device was characterized as "oscillating positive expiratory pressure therapy system." We looked for synonyms in Wikipedia and Google, which resulted in our first PubMed search terms. We started this search in PubMed using the search term "flutter valve"[title] OR "heimlich valve"[title] OR "acapella"[tiab] OR "aerobika" [tiab]. We were not able to find any clinical trial relating to COPD. We found several trials in which patients with bronchiectasis were studied, however these were excluded because they were not the disease process in question. ${ }^{2}-4$ We then searched for "oscillating positive*" [tiab]. There were 31 results, most of which were investigating bronchiectasis or cystic fibrosis patients, which were again excluded. $\underline{-11}$ We felt that the anatomical and pathophysiological processes were too dissimilar to inform the management of our patient. Additionally, we found a trial incorporating COPD patients, but the article had been retracted. $\underline{12, \underline{13}}$ There was one clinical trial with a randomized crossover design. $\underline{1}$ We also found three systematic reviews, so we reviewed the bibliography of those papers looking for any clinical trial involving COPD patients. $\underline{14}-\underline{16}$ This resulted in three more randomized trials (two crossover and one control group) using oscillating pressure for airway clearance. $\underline{17}-\underline{19}$ These three randomized trials used outpatients. All had small sample sizes ( $N=15-20)$. Two of the papers only reported disease oriented outcomes that were thought to be disease oriented, such as FEV1 $\underline{17}, \underline{18}$ The Wolkove paper showed improvement in 6 minute walk test by 30 meters after one week of PEP, but only addressed stable outpatients diagnosed with COPD without exacerbations for at least two months. $\frac{19}{}$ In this particular clinical practice, oscillating positive expiratory pressure devices are not available to outpatients - only inpatients. We chose the Ambrosino paper for review, as the inpatient status of the included cases most closely reflected that of our own patient, who had been hospitalized for acute exacerbation, and as it investigated patientoriented outcomes. $\frac{1}{}$

\section{Critical Appraisal}

This is a randomized crossover trial with 14 cases. Upon closer review, only eight of the 14 cases had COPD, making this trial too small to draw meaningful conclusions. Additionally, we can't separate the COPD patients from those who had chronic bronchitis, bronchiectasis, interstitial lung disease, or silicosis. What the cases had in common was that each produced at least $25 \mathrm{ml}$ of sputum per day. Presumably this was to evaluate sputum clearance using an oscillating positive expiratory device. Each case was randomly assigned to both treatment groups, alternating by which treatment was initiated first. The specific method of randomization was not specified. The two groups were 1) standard therapy with percussion and postural drainage compared to 2) breathing through an oscillating positive expiratory pressure (PEP) device. A confusing and perhaps critical flaw was that these were inpatients, but were not receiving mucolytics, steroids, or antibiotics. Additionally, they were characterized as "stable" on standard therapy for at least one month. Although not explicitly stated, it may be that these patients were hospitalized simply for the purpose of this clinical trial. They were in the hospital for an average of eight days. We don't think that these patients were in a disease state similar to the severity and unstable nature of our patient's condition. This was disappointing because our medical service admits many patients with exacerbation of COPD.

The most patient-oriented outcome was a modified visual analog scale to assess "chest unpleasantness due to secretions." This was measured 30 minutes before treatment, immediately before treatment, at the end of treatment and 60 minutes after treatment. At the start of treatment, the standard therapy group had an unpleasantness score of $46 \% \pm 17$, and this improved to $35 \% \pm 16$ at the end of therapy. The PEP therapy group had an average unpleasantness score of $45 \% \pm 9$, which improved to $37.5 \% \pm 11$. This comparison was not statistically adequate to determine difference, nor did it reach the usual threshold of $10-15 \%$ typically thought of as being clinically significant.

Unfortunately, statistics for the scores after 60 minutes were available in graphical form only. Both groups appeared to have the same, minor improvement at 60 minutes. No comparisons between PEP and standard therapy resulted in statistically adequate differences. 
NOACK DP, NEWTON G. Compared to maximal current management standards, oscillating positive expiratory pressure devices have not been shown to improve clinically relevant outcomes in COPD patients with acute exacerbation. Clin. Res. Prac. 2017;3(2):eP1516. doi: $\underline{10.22237 / c r p / 1498867320}$
Clinical Research in Practice The Journal of Team Hippocrates

VOL 3 ISS 2 / eP1516 / AUGUST 23, 2017 doi: $10.22237 / \mathrm{crp} / 1498867320$

The authors also observed sputum production, FEV1, FVC, and SaO2 but found no differences between the two treatments. These measures could be considered disease-oriented outcomes.

Other measures that would have been relevant, but that were not followed in this study include mortality, length of stay, readmission rates, measures of shortness of breath and the 6-minute walk test, or other standardized exercise tolerance tests. All patients completed the four sessions included in the protocol. There was no blinding in this trial. This is a significant weakness. Despite the potential bias introduced by this study limitation, the authors were still unable to demonstrate benefit from the PEP device. Because there was no difference between groups, we cannot discuss effect size. This is little more than a case series, so we consider this to be Level 4 Evidence according to the Oxford Center for Evidence Based Medicine guidelines.

\section{Clinical Application}

Although we see PEP devices frequently dispensed in the hospital by respiratory therapists, the overall body of evidence for their utility is sparse and not convincing. We are mindful that these devices have financial costs. Without demonstrated benefit beyond conventional therapy, we question the use of these devices in the setting of acute exacerbation of COPD. One could argue that because there was no observed difference between percussion with postural drainage and PEP, this might relieve stress on staffing for respiratory therapists. However, there would be no way to ensure that the patients were using the devices correctly or consistently (we frequently find incentive spirometers that sit unused at the bedside). Also, the patient needs to be cognitively aware and alert to use the device. Routine therapy can be done even in patients that are too weak for prolonged expiration through a PEP device. Although we don't think this would have benefitted our patient or patients like him, we were intrigued by the Wolkove paper for outpatients with stable COPD. Further study is needed before any recommendation can be made regarding PEP devices for patients with COPD.

Lessons learned:

1. Oscillating positive expiratory pressure devices may have benefit in bronchiectasis, but there is no evidence they are effective for acute COPD exacerbations. Evidence suggests they are no better than standard therapy, but this is not reliably demonstrated.

2. Despite no demonstrated benefit in COPD, this is a device that is used often. This is an example of indication creep, when a therapy that is approved and works for one disease is used for a related disease despite a lack of evidence.

3. In the era of Accountable Care Organizations, physicians should speak out against appropriating healthcare resources for therapies that have no proven benefit.

\section{References}

1. Ambrosino N, Callegari G, Galloni C, Brega S, Pinna G. Clinical evaluation of oscillating positive expiratory pressure for enhancing expectoration in diseases other than cystic fibrosis. Monaldi Arch Chest Dis. 1995;50(4):269-275.

2. Figueiredo PH, Zin WA, Guimaraes FS. Flutter valve improves respiratory mechanics and sputum production in patients with bronchiectasis. Physiother Res Int. 2012;17(1):12-20. doi: 10.1002/pri.507.

3. Patterson JE, Bradley JM, Hewitt O, Bradbury I, Elborn JS. Airway clearance in bronchiectasis: a randomized crossover trial of active cycle of breathing techniques versus Acapella. Respiration. 2005;72(3):239-242. doi: 10.1159/000085363.

4. Patterson JE, Hewitt O, Kent L, Bradbury I, Elborn JS, Bradley JM. Acapella versus 'usual airway clearance' during acute exacerbation in bronchiectasis: a randomized crossover trial. Chron Respir Dis. 2007;4(2):67-74. doi: $\underline{10.1177 / 1479972306075483 .}$.

5. Hoo ZH, Daniels T, Wildman MJ, Teare MD, Bradley JM. Airway clearance techniques used by people with cystic fibrosis in the UK. Physiotherapy. 2015;101(4):340-348. doi: 10.1016/i.physio.2015.01.008. 
NOACK DP, NEWTON G. Compared to maximal current management standards, oscillating positive expiratory pressure devices have not been shown to improve clinically relevant outcomes in COPD patients with acute exacerbation. Clin. Res. Prac. 2017;3(2):eP1516. doi: $10.22237 / \mathrm{crp} / 1498867320$
Clinical Research in Practice The Journal of Team Hippocrates

VOL 3 ISS 2 / eP1516 / AUGUST 23, 2017 doi: $10.22237 / \mathrm{crp} / 1498867320$

6. Lee AL, Williamson HC, Lorensini S, Spencer LM. The effects of oscillating positive expiratory pressure therapy in adults with stable non-cystic fibrosis bronchiectasis: A systematic review. Chron Respir Dis. 2015;12(1):36-46. doi: $10.1177 / 1479972314562407$.

7. Mcllwaine PM, Wong LT, Peacock D, Davidson AG. Long-term comparative trial of positive expiratory pressure versus oscillating positive expiratory pressure (flutter) physiotherapy in the treatment of cystic fibrosis. J Pediatr. 2001;138(6):845-850. doi: $10.1067 / \mathrm{mpd} .2001 .114017$.

8. Morrison L, Agnew J. Oscillating devices for airway clearance in people with cystic fibrosis. Cochrane Database Syst Rev. 2009(1):Cd006842. doi: 10.1002/14651858.CD006842.pub2.

9. Morrison L, Agnew J. Oscillating devices for airway clearance in people with cystic fibrosis. Cochrane Database Syst Rev. 2014(7):Cd006842. doi: 10.1002/14651858.CD006842.pub3.

10. Ramos EM, Ramos D, lyomasa DM, et al. Influence that oscillating positive expiratory pressure using predetermined expiratory pressures has on the viscosity and transportability of sputum in patients with bronchiectasis. J Bras Pneumol. 2009;35(12):11901197. doi: 10.1590/s1806-37132009001200005

11. Thompson CS, Harrison S, Ashley J, Day K, Smith DL. Randomised crossover study of the Flutter device and the active cycle of breathing technique in non-cystic fibrosis bronchiectasis. Thorax. 2002;57(5):446-448. doi: 10.1136/thorax.57.5.446

12. Ragavan AJ. Comparing performance of three oscillating positive expiratory pressure devices at similar amplitude and frequencies of oscillations on displacement of mucus inside trachea during cough. Respir Care. 2012. doi: $10.4187 /$ respcare.01631.

13. Notice of retraction. Comparing performance of 3 oscillating positive expiratory pressure devices at similar amplitude and frequencies of oscillations on displacement of mucus inside trachea during cough. Respir Care. 2012;57(8):1358. doi: $10.4187 /$ respcare.02033.

14. Holland AE, Button BM. Is there a role for airway clearance techniques in chronic obstructive pulmonary disease? Chron Respir Dis. 2006;3(2):83-91. doi: 10.1191/1479972306cd097rs

15. Ides K, Vissers D, De Backer L, Leemans G, De Backer W. Airway clearance in COPD: need for a breath of fresh air? A systematic review. COPD. 2011;8(3):196-205. doi: 10.3109/15412555.2011.560582.

16. Hill K, Patman S, Brooks D. Effect of airway clearance techniques in patients experiencing an acute exacerbation of chronic obstructive pulmonary disease: a systematic review. Chron Respir Dis. 2010;7(1):9-17. doi: 10.1177/1479972309348659.

17. Morsch AL, Amorim MM, Barbieri A, Santoro LL, Fernandes AL. Influence of oscillating positive expiratory pressure and the forced expiratory technique on sputum cell counts and quantity of induced sputum in patients with asthma or chronic obstructive pulmonary disease. J Bras Pneumol. 2008;34(12):1026-1032. doi: 10.1590/s1806-37132008001200007

18. Gastaldi AC, Paredi P, Talwar A, Meah S, Barnes PJ, Usmani OS. Oscillating positive expiratory pressure on respiratory resistance in chronic obstructive pulmonary disease with a small amount of secretion: a randomized clinical trial. Medicine. 2015;94(42):e1845. doi: 10.1097/md.0000000000001845.

19. Wolkove N, Baltzan MA, Jr., Kamel H, Rotaple M. A randomized trial to evaluate the sustained efficacy of a mucus clearance device in ambulatory patients with chronic obstructive pulmonary disease. Can Respir J. 2004;11(8):567-572. doi: $\underline{10.1155 / 2004 / 828591}$ 